\title{
Use of a Roth Net Platinum Universal Retriever for the endoscopic management of a large symp- tomatic gallstone causing Bouveret's syndrome
}

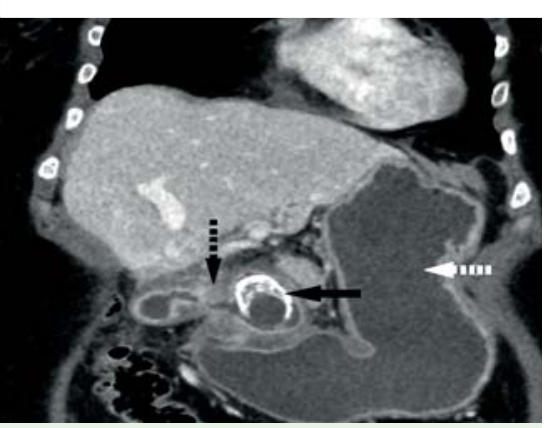

Fig. 1 Contrast-enhanced computed tomography imaging revealed a fistulous communication between the body of the gallbladder and the duodenal bulb (dotted black arrow). A calculus, measuring $3.7 \times 2.2 \mathrm{~cm}$ (black arrow), was seen lodged at the junction of the first and second parts of the duodenum, causing gastric outlet obstruction (dotted white arrow) suggestive of cholecystoduodenal fistula and Bouveret's syndrome.

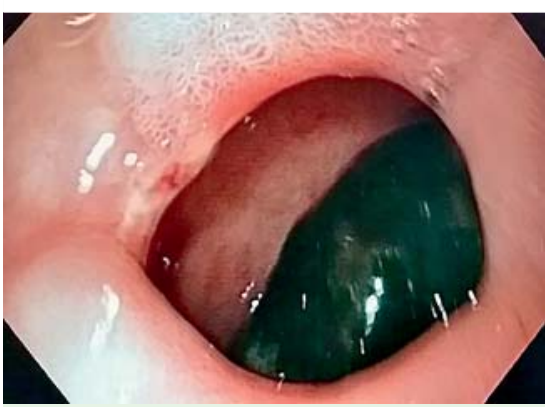

Fig. 2 A large pigmented stone was seen in the duodenal bulb on gastroduodenoscopy.

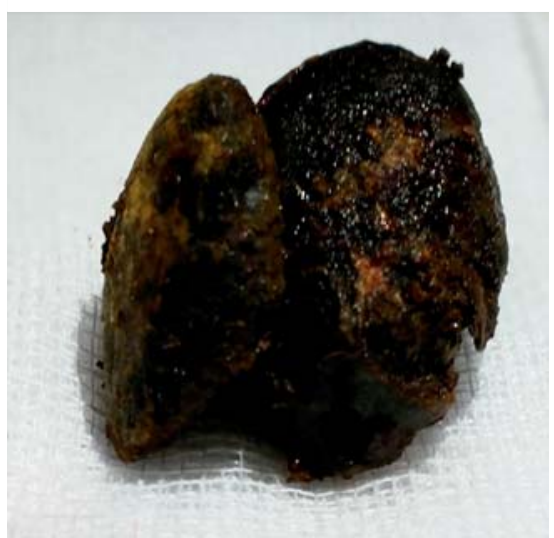

Fig. 3 A large pigmented stone was removed successfully by an endoscopic Roth Net Platinum Universal Retriever (net size $4 \times 5.5 \mathrm{~cm}$, diameter $2.5 \mathrm{~mm}$; US Endoscopy, Mentor, Ohio, USA).
A 65-year-old woman, who was diagnosed with extrahepatic portal vein thrombosis, portal biliopathy, and gallstone disease, presented with multiple episodes of vomiting associated with abdominal pain after meals, with no overt gastrointestinal bleed or jaundice.

Physical examination revealed a malnourished, dehydrated pale patient with a distended upper abdomen without peritoneal signs. Contrast-enhanced computed tomography (CT) imaging performed immediately after hydration to look for extension of portosystemic thrombus revealed a fistulous communication between the body of the gallbladder and the duodenal bulb ( $\bullet$ Fig. 1, dotted black arrow). A calculus, measuring $3.7 \times 2.2 \mathrm{~cm}$ ( $\bullet$ Fig. 1, black arrow), was seen lodged at the junction of the first and second parts of the duodenum, causing gastric outlet obstruction ( $\bullet$ Fig. 1, dotted white arrow) suggestive of cholecystoduodenal fistula and Bouveret's syndrome [1]. Gastroduodenoscopy revealed a large pigmented stone lodged in the duodenal bulb ( $\bullet$ Fig. 2). The stone was successfully removed endoscopically ( $\bullet$ Fig. 3 ) using a Roth Net Platinum Universal Retriever (net size $4 \times 5.5 \mathrm{~cm}$, diameter $2.5 \mathrm{~mm}$; US Endoscopy, Mentor, Ohio, USA) ( $\bullet$ Video 1 ). Less than $5 \%$ of intestinal obstruction is caused by gallstone ileus and $<4 \%$ of those are due to Bouveret's syndrome, which is most commonly seen in frail women [2]. The Rigler's triad (small bowel obstruction, pneumobilia, and ectopic gallstone) is pathognomonic for this syndrome [3], but is not seen in $40 \%$ cases, even on computed tomography. Surgery (enterolithotomy, gastrostomy with or without cholecystectomy, and fistula repair) is the mainstay of treatment, but in poor surgical candidates such as our patient (elderly, malnutrition, portal hypertension with biliary system collaterals), endoscopic therapies such as net/basket extraction, mechanical, electrohydraulic or intracorporeal laser lithotripsy, or a combination of these, can be used, but the success rate is only $9 \%$ [4].

Endoscopy_UCTN_Code_CCL_1AB_2AZ_3AZ

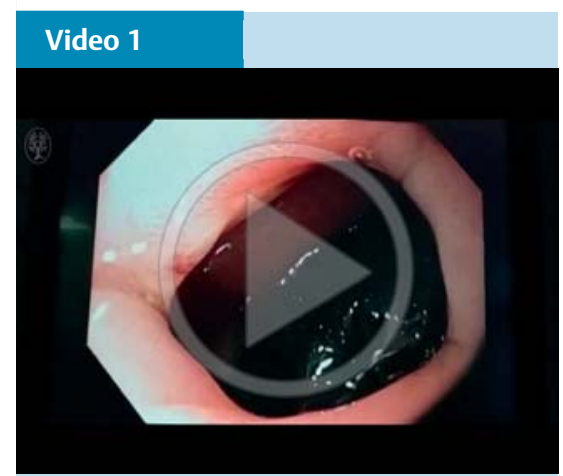

Real time endoscopy showing: large pigmented gallstone impacted at the first part of the duodenum (00.11 seconds); application of the Roth Net (00.32 seconds) posterior to the gallstone; and finally extraction of the gallstone (00.47 seconds). The extracted gallstone is seen in the body of the stomach $(00.59$ seconds).

\section{Competing interests: None}

\section{Ankur Jindal, Cyriac Abby Philips, Kapil Jamwal, Shiv K. Sarin}

Department of Hepatology, Institute of Liver and Biliary Sciences, New Delhi, India

\section{References}

1 Negi RK, Chandra M, Kapur R. Bouveret syndrome: primary demonstration of cholecystoduodenal fistula on MR and MRCP study. Indian J Radiol Imaging 2015; 25: 31 - 34

2 Nuño-Guzmán CM, Marín-Contreras ME, Figueroa-Sánchez $M$ et al. Gallstone ileus, clinical presentation, diagnostic and treatment approach. World J Gastrointest Surg 2016; 8: $65-76$

3 Gaduputi V, Tariq H, Rahnemai-Azar AA et al. Gallstone ileus with multiple stones: Where Rigler triad meets Bouveret's syndrome. World J Gastrointest Surg 2015; 7: 394-397

4 Lowe AS, Stephenson S, Kay CL et al. Duodenal obstruction by gallstone (Bouveret's syndrome): a review of the literature. Endoscopy 2005; 37 : $82-87$

\section{Bibliography}

Dol http://dx.doi.org/

10.1055/s-0042-116430

Endoscopy 2016; 48: E308

(c) Georg Thieme Verlag KC

Stuttgart · New York

ISSN 0013-726X

\section{Corresponding author}

\section{Ankur Jindal, MD}

Department of Hepatology

Institute of Liver and Biliary Sciences

D - 1, Vasant Kunj

New Delhi 110070

India

Fax: +91-11-46300010

ankur.jindal3@gmail.com 